\title{
FROM EMERGENT TO INNOVATIVE RISKS IN FRANCE: SPECIFI- CATION OR STANDARDIZATION OF THE OCCUPATIONAL RISKS OF NANOMATERIALS?
}

\author{
Patrick Chaskiel $^{1}$ 凶 (1) \\ ${ }^{1}$ Professor Emeritus of Communication CERTOP-CNRS, Université Toulouse 3-Paul Sabatier, France \\ 1Professor Emeritus of Communication CERTOP-CNRS, Université Toulouse 3-Paul Sabatier, France
}
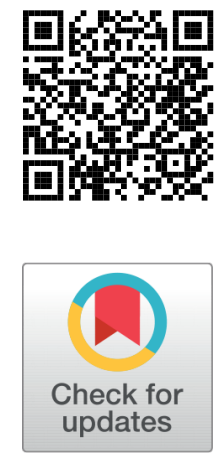

Received 22 March 2021

Accepted 10 April 2021

Published 30 April 2021

Corresponding Author

Patrick Chaskiel, patrick.chaskiel

@univ-tlse3.fr

DOI 10.29121/

granthaalayah.v9.i4.2021.3836

Funding: This research received no specific grant from any funding agency in the public, commercial, or not-for-profit sectors.

Copyright: (C) 2021 The Author(s). This is an open access article distributed under the terms of the Creative Commons Attribution License, which permits unrestricted use, distribution, and reproduction in any medium, provided the original author and source are credited.

\section{ABSTRACT}

The process by which occupational risks in industry and manufacturing emerge has been established as a subject of research in sociology. This oftencontentious process draws on toxicological findings that may or may not be accepted as established, and on epidemiological observations of pathologies. Logically enough, there has been little interest in the toxicological risks of innovative industrial technologies, due to a lack of specific cases. With the development of new technologies such as nanomaterials, the question of risks has been formally raised but has not been addressed in terms of clear toxicological results or epidemiological observations. My goal in this article is to introduce the notion of "innovative risk" to refer to a process of making risks a subject of research and discussion before evidence of health problems has been established. By examining how French labor administrations and occupational medicine organizations monitor such risks in companies and research laboratories, I will demonstrate a tension between, on the one hand, the acknowledged specificity of these risks, and, on the other hand, the standardization of actual oversight. This tension calls into question the ability of research on industrial occupational risks to approach and analyze innovative risks.

Keywords: Nanomaterials, Technology, Innovations, Occupational Risks, Risk Control, France

\section{INTRODUCTION}

In France, scholarly literature has emphasized the complexity of the process by which occupational risks emerge, and in particular the difficulty of establishing pathologies connected to industry and manufacturing. On the one hand, recognition of these risks and pathologies encounters constant resistance from employers Thébaud-Mony (1991, 2007), and problems may be actively covered up 
by government authorities, although this is becoming less common. On the other hand, the mobilization of workers and their union representatives on the topic of workplace health has proceeded very unevenly Moriceau (2009) and, at least until the 1970s, was confined to the context of collective bargaining Omnès (2009).

This closing off of the system of labor relations to occupational risks has gradually been counteracted by media attention and judicial proceedings Henry (2007) and by professional and civil initiatives taken by victims, who often stand in for unions.

It is clear that occupational risks are a topic of increasingly intense socio-political interest Bouffartigue (2014). However, the publicization of risks has for the most part been tied to identifiable pathologies and localized industrial activities that have been constituted and made visible as occupational health problems. Although achieving institutional recognition of such pathologies has been a contentious process, the terrain on which such conflicts take place has been mapped.

In keeping with this, sociological research on industrial occupational risks has generally focused on problems that are "justified" by toxicological information or epidemiological observations, even when these are unclear Counil and Henry (2018). Approaches based on such observations and information take a retrospective view that tends to ignore new scientific and technological developments and innovations.

This lack of attention contrasts sharply with the intense controversies that nowadays surround technological risks-including occupational risks-even before innovation occurs. Thus, we observe a discrepancy between contestations of new technology as soon as it is conceived and the ability of social theories to provide analytic frameworks for such debates before occupational risks have been connected to pathological or toxicological findings.

In this respect, the notion of emergent risks, considered in terms of how pathologies become topics of debate and research, is insufficient: occupational risks may emerge as topics without reference to any identification or localization of these risks, and without being based on even preliminary toxicological results or pathological observations. We must overcome this insufficiency by going beyond the notion of emergent risks and developing the notion of innovative risks.

The notion of innovative risks as I am proposing it here refers to debates over scientific-technical projects that may lead to occupational health problems that have not yet been scientifically assessed or epidemiologically observed. Thus, not all innovations correspond to innovative risks-for example, when they involve equipment, materials, or chemical substances that are already (relatively) well known.

I use the term innovative risks because these risks are doubly undefined. First, due to the novelty of the problems posed, there is no definitive data available in terms of toxicological assessments; and second, the possibility of evaluating them is itself uncertain. We might also call them "breakthrough risks" by analogy to the vocabulary of technological innovation. Because of this double uncertainty, they cannot be studied using classical approaches or treated with certainty by existing modes of prevention. 
The subject of nanotechnology, and nanomaterials more specifically, ${ }^{1}$ is emblematic of this characterization of innovative risks, which have rapidly become issues of occupational health Chaskiel (2013). On the one hand, controversies arose immediately after major nanotechnology programs were launched in the late 1990s, even before it was clear what the applications of nanotechnology would be. On the other hand, attempts to regulate Lacour (n.d.) and evaluate the toxicity or environmental harmfulness of nanomaterials raised questions without answers, due to a lack of adequate evaluation methods Ferron et al. (2015). All the various initiatives seeking to control nanomaterials, with their regulatory grey areas, are indicative of the difficulties of regulating nanomaterials: although such initiatives have been in place for an extended period of time, they have not provided any definite solutions. ${ }^{2}$

There is little research available on whether practices of occupational risk management are adequate for the health questions surrounding nanomaterials. Some studies have shown that risk management may evolve on a case-by-case basis, voluntarily Éric Drais (2017); L'allain et al. (2015). But the task of theorizing the issue of risk management in the face of the double uncertainty of innovative risks still lies ahead of us.

Thus, we can observe a tension between, on the one hand, the widely accepted particularities of the risks of nanotechnologies, and, on the other hand, the standardization of methods for handling them in workspaces. Indeed, debates over nanomaterials have shown that they cannot be evaluated using the classical principle of the dose-effect relation, but rather that risk prevention must be based on the precautionary principle Chaskiel and Suraud (2014). Nevertheless, in terms of administrative and medical oversight, management of the occupational risks of nanomaterials appears non-specific, even banal.

Research on the usage and spread ofnew science and technology encounters a significant methodological difficulty: on what experiments or fieldwork can such research base itself? The present work is not exempt from this difficulty; I have had to take into account the difficulty of "situating" or locating innovative risks. To deal with this difficulty, I have chosen to take the point of view of the oversight of risk management by the state administration or by occupational medicine, both of which have received repeated warnings of a health catastrophe that could be on par with that caused by asbestos. This analytic perspective is based on the idea that management of occupational (as well as environmental and health) risks depends largely on public and institutional pressure, since, as Luhmann put it, industrial organizations code their operationsso as to ensure that their expenses will be recouped Luhmann (1995). In other words, insofar as safety is not productive, it represents a cost that companies cannot turn into profit. As a result, companies cannot spontaneouslythat is, without outside "irritation" - take on problems such as occupational health,

\footnotetext{
${ }^{1}$ Nanotechnology refers to the use of nanomaterials for the particular properties they have at the nanoscale in various applications.

${ }^{2}$ Since 2004, there have been multiple initiatives, heavily funded by the European Union, such as Nanosafe1 and Nanosafe2-demonstrating both the importance and the scope of the problem.
} 
as the history of occupational health shows.

In concrete terms, my research on this topic ${ }^{3}$ was for the most part carried out between 2013 and 2016 and incorporates 33 interviews. I interviewed officials from labor, environmental, and health departments, members of science and technology organizations, manufacturers, labor unionists, occupational physicians, and health and safety experts about actions they had taken with respect to nanomaterials. These interviews were strictly anonymous, since there are only a few experts on nanomaterials, and they would otherwise be easily identified. The fact that there are so few experts on this subject is in itself indicative, and confirms my thesis that, in the field, the potential risks of nanomaterials are trivialized.

Most of the interviews were quite extensive (between one and four hours, in person), but four of them were quite short (just a few minutes, over the phone)revealing the inaptitude of administration officials or occupational physicians to tackle questions regarding the risks of nanomaterials, an inaptitude they themselves explicitly recognized. Furthermore, some interview requests were rejected or carefully dodged by companies and organizations doing technological research-but never by members of university laboratories. Of course, it is difficult to provide a rigorous explanation for such refusals (in order to do so, one would have to conduct interviews with the people avoiding them...), but they did occur more frequently than in the context of other research (for example, my research on risks in the chemical or nuclear industries). They confirm the opinion shared by many administration officials that a particular shroud of secrecy about matters relating to nanomaterials surrounds the industry. For example, one official told me, in reference to a professional conference held in 2013, "we couldn't get the companies to take the stage; they told us 'we'll be there, we're interested,' but we didn't hear from them there" (Regional labor department official). After publicly making developing nanotechnologies an article of faith, companies have clearly opted for a policy of non-communication.

My research also draws on participant observation of groups of experts (beginning in 2012 until 2019) and, between 2014 and 2016, within the CHSCT (Comité d'hygiène, de sécurité et des conditions de travail; Committee on Health, Safety, and Working Conditions) of a major scientific institution that includes laboratories working on nanomaterials. I was present at more than 60 meetings. Finally, my work has benefitted from many informal conversations, which, as we know, are extremely informative, given the relative freedom with which people tend to speak in such contexts.

On the basis of this research, I will show, first, that there is a major obstacle in accounting for nanomaterials: "situating" occupational risks beyond what is flagged by public debates. This problem of "situation" has to do both with tracking activities related to nanomaterials and with interpreting the issues raised. Next, I will demonstrate that this lack of "situation" leads to the standardization of nanomateri-

\footnotetext{
${ }^{3}$ This research was funded by a French public agency, Anses (Agence Nationale de Sécurité Sanitaire de l'Alimentation, de l'Environnement et du Travail).
} 
als as occupational risks, because of a lack of specific capacities for action. Finally, I will examine the possibility of overcoming this paradox, drawing inspiration from the Collingridge dilemma Collingridge (1980), which, applied to the present topic, states that, on the one hand, innovative risks are not formalized and, on the other, it will be difficult to counteract them if they turn out to constitute clear health hazards once the activities in question have been developed at a large scale.

\section{SITUATING NANOMATERIALS}

Since the launch of major nanotechnology programs in the 2000s, nanotechnologies have been presented as generic technologies-that is, as having the potential to be used in any number of activities and products. As a result, sociological research on them has faced a "situation" problem.

\subsection{MATERIALS MORE DIFFUSE THAN DIFFUSED}

Far from having fulfilled the euphoric economic projections made by for-profit think tanks, ${ }^{4}$ the industrialization of nanotechnologies has proceeded more slowly than predicted.

Nanotechnologies have, of course, been defined as technologies of the future through the announcement of innovative applications, which the "astonishing" properties of materials at the nanometric scale would make possible. Applications such as nano-vectors for medications, medical prostheses, energy-efficient screens, and new technology for storing energy have all been used as examples, especially during the height of the controversies.

But, "nanomania" notwithstanding, industrial development of these projects for innovation has proceeded more slowly than forecasted-technical and industrial realities are immune to predictions. Although the notion that nanotechnology will be widely used has been repeated since the launch of nanotechnology programs, there is no basis for it: some fifteen years after its founding in the 2000s, the National Nanotechnology Initiative (NNI), in its 2014 " 2.0 " version, ${ }^{5}$ is focused on the goal of commercializing "nanoproducts" - proof that they are still not widely used in industry and that the technology itself has not developed. Studies done by the French Ministry of Economy show the minimal economic impact of nanomaterials, particularly in terms of manufacturing jobs-about 5000 in France in early 2010s Les réalités industrielles dans le domaine des nanomatériaux en France Analyse de la réalité du poids des nanomatériaux dans la filière industrielle concernée (2012). No reliable study has contradicted the marginality of "nanotech" jobs in France, and other studies attest to the slow industrialization of nanomaterials.

\footnotetext{
${ }^{4}$ In 2008, some estimates predicted that by 2015, 3000 billion dollars' worth of products would be in circulation-more than the GDP of France. These statistics have often been uncritically repeated by both promoters and opponents of nanotechnologies, with both sides exaggerating the issue, either positively or negatively.

${ }^{5}$ PCAST 2014, https://www.nano.gov/node/1243.
} 
Although carbon nanotubes ${ }^{6}$ were emblematic of the application possibilities for nanotechnologies - and of alarm over their risks (which was based on a comparison between their physical, rather than physical-chemical, properties with those of asbestos fibers) - their commercialization was a failure, at least provisionally, and led to the closure or reduced operations of pilot workshops. "There is no commercial market in Europe for nanotubes" (Manufacturer). ${ }^{7}$ Furthermore, controversies have led companies to stop using the word "nano" as an expression of the technological future: "On some company websites, you used to see 'nano'-now it has all disappeared" (Labor administration health and safety expert). Consequently, it is difficult to even locate nanomaterials produced or used.

The difficulty is exacerbated by the fact that "nanomaterial" is a size limit (approximately $100 \mathrm{~nm}$ ), which, in industrial technology, does not directly pre-determine the properties required of an application or a substance. It may be that scale has little impact on made-to-measure manufacturing: "I don't do nano just for the sake of doing nano" (Head of a small/mid-sized company). Achieving the properties required by a client might lead manufacturers to "settle for" the micro-level. Thus, nanometric scale and the size of particles are not systematically foregrounded as such in the search for technical solutions, especially because fear of future regulations has a chilling effect on any technological enthusiasm around them.

The idea that such regulations might eventually be created influences the development of applications, through an anticipated threshold effect connected to the $100 \mathrm{~nm}$ limit that formally separates the nano- from the micro-. Consequently, "I hardly have any market demand for particles under 100 nm" (Startup director). This tendency is not absolute, but it demonstrates a difference between the properties developed in laboratory research and the use of these properties by industry. Such gaps between research and industry are common, but in this case, socio-political and institutional uncertainty is also a factor.

Uncertainty around new materials and applications is especially significant because some older materials that have already been in use for dozens of years have now been re-categorized as nanomaterials.

\subsection{THE RE-CATEGORIZATION OF OLDER MATERIALS}

Lacking sufficiently industrialized innovations to which to refer, debates have, in fact, focused on materials and technologies that were already in widespread use-which may seem paradoxical given the scientific and technological novelty usually brandished by "nano" programs.

These types of applications involve materials that empirical research allowed manufacturers, beginning in the 1980s, to highlight-without ever explicitly refer-

\footnotetext{
${ }^{6}$ These are tubes with nanoscale diameters that may have one or more chambers, and whose properties of mechanical resistance and electrical conductivity are much higher than those of microscale forms of carbon.

${ }^{7}$ See also "Les nanotubes ne sont plus à la fête," Usine Nouvelle, https://www.usinenouvelle.com/ article/les-nanotubes-de-carbone-ne-sont-plus-a-la-fete.N197727, 30 May 2013.
} 
ring to nanoscience-as being more desirable the smaller their particles were: for example, paints that could stick to walls better, or had a more homogeneous color. Such materials were often used as coatings or additives: for instance, nano-silver as a biocide; nano-titanium dioxide $\left(\right.$ nanoTiO $\left.{ }_{2}\right)$ to prevent polluting deposits on cement; or, in an entirely different sector, the additive E171 to make candy shinier and thereby more appetizing.

These materials - at least some of them-have been institutionally transformed into nanomaterials as a result of the adoption of a regulatory definition of nanoscale substances following the recommendation of the European Commission: ${ }^{8}$

"Substance at nanoscale": substance as defined in article 3 of EC regulation no. $1907 / 2006$, intentionally produced at nanometric scale, containing particles, in an unbound state or as an aggregate or as an agglomerate and where, for a minimum proportion of particles in the number size distribution, one or more external dimensions is in the size range $1 \mathrm{~nm}-100 \mathrm{~nm}$. (Decree no. 2012-232 of 17 February 2012; available in English in The Official Journal of the French Republic, Text 4/44, 19 February 2012).

In addition to creating discrepancies in the institutionally established size range for the materials in question, ${ }^{9}$ this sociopolitical definition Henry (2017) of nanomaterials led to the establishment of a registry to catalogue them. The formal decision to create such a registry came after a public debate held under the auspices of the Commission Nationale du Débat Public (National Commission for Public Debate; CNDP) between October 2009 and February 2010, but the idea for it was older than that: "In general, when a formal public debate is launched, the government has some idea of what it will lead to" (official from the Ministry of the Environment). This registry, called the R-Nano Registry, ${ }^{10}$ requires that nano-substances produced and sold at a rate of more than 20 grams per year must be declared. One consequence of this requirement has been that nanomaterials that were not known to the very companies using them are now visible: "We had companies that were absolutely floored to learn that there were nanomaterials in their products" (Start-up director).

of course, some companies are experts in nanotechnology: small or mid-sized companies or industrial groups that often act as intermediaries in the supply chain. The general meaning of the institutional definition does not escape companies that have expertise in nanomaterials as a result of their research and development ( $R$ \& D) activities, and it does not necessarily create technical difficulties in terms of making nanomaterials visible internally, since these companies have adequate tools for defining these materials physico-chemically. ${ }^{11}$ Some of these companies-those that

\footnotetext{
${ }^{8}$ This recommendation was in the process of being reformulated in the late $2010 \mathrm{~s}$.

${ }^{9}$ In particular due to disagreement over the proportion of nanoparticles to take into account in a substance. The higher this proportion is, the greater the number of substances entering into the category of nanoparticles will be. Other elements are also disputed, for example, its limitation to include only nanosubstances that are intentionally produced or used, thereby excluding residual substances.

${ }^{10}$ https://www.r-nano.fr/.

${ }^{11}$ However, some microscopic tools-optical microscopes, for example-do not allow one to see nanoparticles. Thus, by choosing to use instruments that cannot capture nanoparticles, one can claim
} 
are part of industrial groups-were able to actively influence the definition of nanomaterials, as companies have done in other domains Brice (2013); Henry (2017). When this was the case, these companies were content with a complicated definition, which presents the advantage of being difficult to apply since it is hard to understand and to interpret.

In small and mid-sized companies that are not specialized in nanomaterials, and which use "powders," nanomaterials do not always appear clearly. For example, vendors might toy with the requirement to "provide" information about nanomaterials by interpreting this to mean making information available "somewhere," perhaps on a website. They also put the burden of responsibility on their clients or users to make the effort to find out about the presence of nanoparticles, without drawing their attention to it (Health and safety expert). Thus, it is possible that companies, at certain points in the supply chain, do not "see" the nanomaterials in their products.

\subsection{SITUATING NANOMATERIALS FROM THE OUTSIDE}

Although the nanomaterials registry was created in part in response to demands by associations and unions, the raw data in the registry is kept confidential. ${ }^{12}$ Publicization of data is thus limited to tonnage bands for various categories of materials (for example, carbon black, titanium dioxide, amorphous silica, etc.), but there is no way of accessing information about the production, usage, location, or toxicity of these materials in commercial products. In principle, the registry could have been a useful resource for situating the production and use of nanomaterials, but restrictions on access to raw data and a lack of institutional oversight of risk management constitute major obstacles to this.

State and public expertise organizations do have the right to access the raw data, but only the Ministry of the Environment has direct access codes to the registry; all other departments - in particular, labor departments - have to submit an authorization request. However, since the environmental administration does not have clear, structured directives for acting, in practice, it does not take advantage of its ability to access data directly.

As for the labor administration, although its access is not forbidden, it is complicated-that is, when officials happen to make a request. In fact, very few of are active on the matter, and surveys on worker exposure carried out by occupational health organizations have received very low response rates, even in regions where asbestos was widespread (Occupational physician-inspector). Unexpectedly, though asbestos served as a reference point for sounding the alarm on nanomaterials, the health crisis linked to asbestos can have a paradoxical effect on the ground, by serving to marginalize nanomaterials: "We still haven't managed to deal with asbestos, so nanomaterials..." (Occupational physician, telephone interview). Even

that they are absent from materials.

12 I experienced this when I had to sign a confidentiality policy when I participated in a working group on potential use of the data. 
for mass-produced and widely used nanomaterials such as nano-titanium dioxide, officials from the labor administration state that they lack information: "I don't know who has these substances, I don't have the list of the companies concerned" (Occupational physician-inspector.) Standard tools such as Safety Data Sheets (SDS) also do not facilitate locating nanomaterials.

Although regulations state than an SDS is supposed to inform company leaders, occupational physicians, workers, and labor union representatives about the risks of a product, reading an SDS is not clear-cut when it comes to nanomaterials: "We discussed [nanomaterials] within a scholarly association of occupational physicians. Not one of them was able to find nanomaterials on an SDS" (Occupational physician). Insofar as occupational physicians often translate SDS's ${ }^{13}$ for workers and company leaders, their inability to see nanomaterials implies their non-existence as issues of occupational risk. Thus, occupational medicine does not often come into contact with nanomaterials: "I've never encountered nanomaterials, I thought it would happen but..." (Physician and coordinator of an inter-company department covering 236,000 workers). This ignorance regarding the presence or absence of nanomaterials in workshops is confirmed by the lack of mention of nanomaterials in risk evaluation documents [DUER - document unique d'évaluation de risques; single risk-evaluation document $]^{14}$ : "they never appear in DUs, no matter the size of the company" (Ibid.). Although other cases may offset this one, it nevertheless remains true that nanomaterials are not easily identified.

Thus, while dust created by welding or sanding, for example, is a recurring topic of discussion within companies, and is subject to preventive techniques such as vacuuming, the topic is not immediately tied to nanomaterials, despite the fact nanoparticles probably make up some proportion of this dust. This is especially true because, as one occupational physician put it, focusing on the toxicity of products is generally "complicated" and "time-consuming" given the aptitudes and knowledge that must be acquired and the time it takes to do so. This is not easy to do within a profession structured around medical visits Marichalar (2014) — which is the case as a result of ongoing demands from some labor unions (Occupational physician).

Without technical assistance, mobilization around a problem as vague as that of nanomaterials simply will not catch on. Whereas labor organizations have succeeded, in office contexts, in taking ownership of topics such as occupational psychosocial risks, in industrial contexts they rely on occupational medicine to determine issues of toxicity. Where mobilization does occur, it is around nano-objects that have received media attention, such as carbon nanotubes, ${ }^{15}$ which cause alarm without necessarily being linked to any identified pathologies.

\footnotetext{
${ }^{13}$ There can be hundreds of these documents in a small to mid-sized company with several dozen employees.

${ }^{14}$ The Document Unique d'Evaluation des Risques is a required document summarizing all the risks to which a company's staff is exposed.

15 "Récidive dans l'usage des nanotubes, de carbone à Innovation Works sans protection et sécurité des salariés!", CGT EADS leaflet, Suresnes, 8 October 2013.
} 
Given the difficulty of situating and locating nanomaterials within industry, it is to be expected that they are not likely to be factored in as risks.

\section{OVERSIGHT OF RISK MANAGEMENT?}

When public questions about the toxicity of nanomaterials were raised shortly after nanotechnology programs were first launched, they mostly focused on health and environmental risks, and came from environmental NGOs such as Greenpeace or Friends of the Earth. ${ }^{16}$ The issue of occupational health was raised only later, as an extension of negotiations over the REACH regulation, which led to a rapprochement between European NGOs and the European Confederation of Unions Chaskiel (2013). It rapidly became obvious that nanotechnologies involve occupational risks, especially at a time still marked by fallout from the problem of asbestos.

Although the creation of the R-Nano registry has improved the localization of nanomaterials by their producers, it has not led to a specific transformation in the way risk management is supervised, including within academic research laboratories.

\subsection{FROM SCIENTIFIC RESEARCH TO RISKS}

Within research labs, scientific knowledge about nanomaterials does not come from any institutional definition, even though labs are bound by the obligation to declare nanomaterials to the R-nano registry through a procedure centralized by the CNRS [Centre National de la Recherche Scientifique; National Center for Scientific Research]. The goal of thiscentralization is to avoid "endless discussions over definitions" (Health and safety official at a research institute). But filling out this declaration appears to researchers above all as just "more paperwork" (Researcher).

Knowledge about nanomaterials, their properties, and their (eco-)toxic effects comes from various disciplines within the nanosciences, and belongs to a heterogeneous milieu Jouvenet (2012) that varies depending on whether the goal is to create nanomaterials or to study their toxicology Johansson and Boholm (2017); Kelty (2009).

In laboratories where nanomaterials are created, the association between nanomaterials and risks is far from spontaneous. It often arises in response to public debates or, rarely, through the personal initiative of a researcher concerned about his or her health (Researcher).

Initially, pointing out the possible risks of nanomaterials was seen as a threat to the development of research: "[In 2002], a colleague pulled me aside and said, 'You're a pain in the ass with your nanos, you're going to get our research cancelled.' It's become so-and-so who creates the risk, not the nanos" (Researcher). In this respect,

\footnotetext{
${ }^{16}$ In France, in the early 2000s, the first protests came out of anti-tech ideology or criticized the lack of transparency in public funding for industrial innovation, but did not immediately focus on health or environmental risks.
} 
the attitude toward risks in the scientific milieu is akin to the attitude that, until the 2000 s, led businesses and workers to avoid environmental scrutiny.

As a result, the issue of risk is mostly outsourced. For example, within laboratories, nano-residues are handled by companies specializing in the collection of "hazardous waste," which gather them along with other waste and take them to incineration centers where they are destroyed at very high temperature (Waste facility official). However, no assurances are given (or requested) as to the fate of these nanoparticles, thus creating a disconnect between processes of research and processes of waste management.

Even when,at the instigation of funding organizations that take public controversies seriously, the connection between nanomaterials and risk is taken into account within research projects, it does not immediately lead to the establishment of adequate measures within the laboratory. Researchers' lack of appetite for risk management issues - which are often reduced to questions of logistics-is part of a long tradition of ignoring the dangers of research in favor of scientific productivity.

This tendency is gradually being reversed as part of a movement toward making research work safer, including work on nanomaterials Borelle and Pélisse (2017). This trend is the result of pressure from laboratories' supervisory bodies, which are confronted with the prospect of criminal proceedings, and safety is of growing concern within a milieu previously little attentive to it. The practice of handling nanomaterials out in the open is disappearing, replaced the by use of gloveboxes. Mechanisms for prevention are modernized on the basis of the available data, which comes from expert agencies or other organizations ${ }^{17}$ with technical expertise in "nano risks." In this regard, the specificity of nanomaterials in terms of risk management does not come from any procedure internal to labs, and few questions are raised about the reliability of equipment. The recommendation that two layers of latex gloves be worn (because they degrade and can become permeable to particles as a result of sweat), or that particles be vacuumed from top to bottom in order to speed up their fall, are not widely followed or even known within research departments handling nanoparticles (Researchers and health and safety experts).

Scientific mastery of the properties of nanomaterials does not go hand-in-hand with expertise on their potential risks or on the most adequate-or at least most recommended-solutions to these risks. Although labs in France are for the most part structured as state organizations, and researchers are thus protected from the threat of losing their jobs, scientific activity is seen as fitting poorly within administrative constraints: "we can't come in at night anymore; research is its own kind of profession, and enthusiasm doesn't keep business hours" (Researcher). Safety rules in the workplace thus seem to hinder scientific productivity, and in terms of denials of risks, there is no significant difference between labs and factories: "If you take precautions, you're kind of considered a wimp" (Researcher). The issue of safety

${ }^{17}$ Such as the Institut national de l'environnement industriel et des risques (Inéris), the Institut National de Recherche et de Sécurité (INRS) or the Commissariat à l'énergie atomique et aux énergies alternatives (CEA). 
usually takes a backseat to that of working conditions: in the CHSCT of scientific research organizations or academic departments, "it's psychosocial risks that get the most attention" (Health and safety experts from research organizations and author's participant-observation).

Because the milieu is not inclined to worry about risks, only institutional monitoring that circumvents the scientific aspects of the profession seems capable of promoting risk oversight by health and safety experts, or by heads of research departments. Hard and fast regulations, although often judged to be the only way of "getting things to change" (Health and safety expert) are not necessarily capable of counteracting a tendency to neglect risks, when they are applied in a hostile milieu and not enforced in a centralized manner.

\subsection{UNRELIABLE INSTITUTIONAL MONITORING OF RISK MANAGEMENT IN THE WORKPLACE}

Faced with questions from regional departments, which themselves receive information requests from companies and labor unions- "We could have been asked to participate in the CNDP debate [2009-2010] but I crossed my fingers that we wouldn't be" (Health and safety engineer, regional labor department) - the Ministry of Labor isstudying how to respond tothe specific characteristics of nanomaterials. No doubt it was in response to the alarm sounded by the Ministry of Labor that multiple action plans have been included in the Plan National Santé Environment (National Health and Environment Plan, PNSE) and that a study has (slowly, and gradually) begun to monitor a cohort of workers exposed to nanomaterials. ${ }^{18}$ This suggests that exposure to nanomaterials might become the next major health problem that occupational medicine tackles (Interview with an occupational physician/health and safety expert.) However, although nanomaterials are the subject of public debates, it is only with difficulty that they become objects of action by labor administrations.

In February 2008, an internal note ${ }^{19}$ from the Ministry of Labor responded to various requests by invoking the general regulations in force on dangerous chemical agents. While drawing attention to the specificity of the possible toxicity of nanoparticles, its recommendation consisted simply in applying the existing regulations on CMRs (carcinogenic, mutagenic, reprotoxic substances). The document amounted to a reminder of employers' obligation to protect workers and to guarantee that protective equipment is adapted to the sources of risks.

But making good on this guarantee requires a level of technical knowledge that was not widely available in the late 2000 s, and is scarcely any more so today. Verification of the compatibility of protective equipment-gloves, for example-with nanoparticles rarely occurs (Occupational physician/health and safety expert).

\footnotetext{
18 The Epinano program, which faced practical difficulties in accessing workspaces (I was asked to help overcome these obstacles, but this help was not very successful, at least initially).

${ }^{19} \mathrm{http}: / /$ www.intefp-sstfp.travail.gouv.fr/datas/files/SSTFP/Circ_DGT_18\%20f\%C3\%A9vrier\%20 2008\%20Particules\%20nanom\%C3\%A9triques.pdf.
} 
Worker protection primarily involves implementing methods of oversight that have already been mastered: nanomaterials are treated like fine dust or particles: "We have a framework for fine and ultrafine particles, we have experience with them" (Ministry of Labor official). Absence of exposure becomes the main criterion in risk evaluation; it is left to scientists to determine toxicity, if any. One result of this position is that, if there is any doubt, a product is considered a CMR: "For CMR substances, any dose is carcinogenic; so we use that as a reference point, since for nanomaterials, there is no dose-response relationship" (Health and safety expert, labor administration.) But this line of thinking cannot hold up in light of the toxicological complexity of nanomaterials, which is increasingly affirmed and accepted.

In 2009, an inter-regional group of occupational physicians and health and safety experts was established at the instigation of the Ministry of Labor in order to confront and, if possible, surmount, the obstacle presented by the specificity of nanomaterials. Organized on a voluntary basis, these physicians-experts showed themselves to be more sensitive than others to controversies over nanomaterials. However, the group's makeup did not correspond to the technological or industrial reality of the field since, for example, it did not include any members from the Rhône-Alpes region, which is heavily involved in nanotechnologies.

This group reflects the confusion that characterizes ministerial policy on monitoring occupational risks at a time when debate is intense but is not necessarily echoed within the context of labor relations. For example, at the national Conseil d'Orientation sur les Conditions de travail (COCT; Advisory Council on Working Conditions), "we talked about nanomaterials maybe once in two and a half years" (Ministry of Labor official). Within companies, concrete oversight of risks is implemented very slowly, and only occasionally, and the (rare) questions raised by CHSCTs go unanswered (Labor unionist).

In principle, occupational health and safety experts or occupational physicians could fill in the gap in a situation in which "You have on the one hand people who are experts and have over 10 years of post-graduate study on the subject, and, on the other, the workers doing the work" (Labor administration occupational health and safety expert). But neither inspectors nor physicians have points of reference to draw on-for example, a threshold limit value for occupational exposure, which, while not a perfect solution Henry (2017), would serve as a lever for action.

This lack of reference points weakens the ability of labor inspectors to act, since their work depends first and foremost on regulations. Indeed, the technical complexity of the issue of nanomaterials is in tension with inspectors' areas of expertise, which are usually regulatory and rarely scientific or technical Mias (2015). Inspectors do not have command of scientific knowledge or even of the appropriate technical language (Labor administration health and safety expert). In other words, in spite of the public debates that ensure that nanomaterials remain in the spotlight, a fundamentally regulatory approach cannot be used to take hold of a topic too unclear to be taken out of the strictly scientific-technological context and transferred into the 
workplace.

The difficulty in dealing with nanomaterials other than in standardized terms, and in the absence of observed-or even evoked-harmfulness serves to marginalize them in comparison to other visible and evaluable risks such as falls from ladders, which can be counted, CMR substances which can be identified and for which texts and instructions are available, and psychosocial risks, the pathologies of which can be described by workers themselves. This "competition" between risks, which is made official by their respective prioritization in prevention policies, is not propitious for commitment and investment of time, which end up being matters of personal choice for supervisors.

Indeed, when labor administration officials or physicians take an interest in nanotechnologies, it is often out of personal desire or curiosity (Occupational physician), and involves activities such as collecting digital documents or attending public meetings or seminars - and does not thereby becoming operational. In practice, initiatives to frame the risks of nanomaterials are halting, including by officials with technical, scientific, or medical expertise. Some relatively well-informed inspectors will draw a connection, for example, between clean boots at a construction site and the presence of nanomaterials such as nano-titanium dioxide, which prevents stains. However, making this connection does not directly lead them to raise the issue of the use of nano-titatium dioxide as a wall coating to prevent air pollution (exhaust gas). Where guides for identifying nanomaterials on the basis on their functionalities do exist Aide au repérage des nanomatériaux en entreprise (2014), they only become operational on a voluntary basis.

To the extent that these technical guides are favored by the central labor administration over very general texts (Ministry of Labor official), physician-inspectors are better placed than inspectors trained in laws and regulations to tackle the subject, because the medical profession, and the advice it can provide, opens company doors more easily. Thus, medical inspectors appear more capable than other administrative officials of tackling various problems related to nanomaterials (Physicianinspector). However, even if having medical expertise can contribute to developing "know-how" with respect to nanomaterials, it cannot lead to "knowing-what-to-do": "We treat workers exposed to nanomaterials just like everyone else" (Occupational physician with an intercompany department in an industrial nanotechnology district, telephone interview.)

This trivialization of nanomaterials is all the more common since the European regulation $\mathrm{REACH}^{20}$ does not predispose actors to tackle the subject.

\footnotetext{
${ }^{20}$ Registration, Evaluation, Authorization and Restrictions of Chemical Substances. The European Union adopted this regulation in 2006, https://echa.europa.eu/fr/home.
} 


\subsection{FROM REACH TO NANOMATERIALS: THE OBSTACLE OF TECHNICALITY}

The conditions in which REACH developed have been studied Jouzel and Lascoumes (2011), but only rarely has REACH been examined at from the point of view of its application and its effect on the topic of risks. Nevertheless, although prevention has been the long-standing basis for oversight policies, the REACH regulation formalizes another principle, precaution, expressed in terms of the motto "no data, no market." Thus, REACH requires industry to provide data in order to preserve or obtain the ability to use materials. This requirement, regardless of its scope, has revealed the gap between the knowledge about toxicity industry claims to have and the knowledge it actually has: "In Europe, we really only know about a few dozen chemical products out of 135,000...The companies tell us 'we know our products,' but ultimately, we've realized that no, they don't" (Labor administration official).

In the early days of REACH, many manufacturers took a distant or even disdainful attitude toward "one more regulation" that would never be applied. The threat that certain substances might be put on the "candidate list" in Appendix 14 to REACH - that is, potentially made subject to a very exceptional usage authorization, or banned-nevertheless ultimately influences technological programs: for example, aircraft manufacturers' "chrome-free" projects, though anterior to REACH and not solely European, reflect this influence Chaskiel and Klein (2017). ${ }^{21}$

However, although REACH directly influences the use of well-known and widespread materials, when it comes to nanomaterials, the regulation does not create tools for risk surveillance. More so than the thresholds that set institutional procedures into motion and limit the number of nanomaterials considered, to the extent that nanomaterials are most often still being developed, it is above all the technical procedure for evaluating toxicity that is problematic, because it is not conclusive Ferron et al. (2015). The most relevant idea-but also least practical-is that each nanoparticle constitutes its own case. Given the thousands of possible cases, this means it would take at least 50 years to provide valid assessments of toxicity just for the nanoparticles that currently exist (Researcher)—not to mention those still to be created.

This indeterminacy of nanotoxicology confirms a trend toward the increased technicality of occupational health issues. Far from having simplified access to toxicological data, REACH is a tool "that requires an advanced degree" and, for nanomaterials "we are reaching a level of incredible technical complexity" (Health and safety engineer), which makes it very difficult for regulations to be operational on the ground.

Consequently, although the choice between adapting or transposing REACH to specifically address the issue of nanomaterials has created a divide between industrial and institutional decision-makers on the one hand and labor organizations and

\footnotetext{
${ }^{21}$ In laboratories, there is an obligation to take into account the eventual technological and industrial uses that may be made of research on materials and to orient research accordingly-without this having any effect on how risks are managed within the lab itself, as we have seen.
} 
NGOs on the other, this divide remains relatively abstract, because the existence of more fine-grained regulation would not resolve the problem of how to evaluate risks within production spaces. Nor would it give risk controllers tools or means of action to use on the job, given the difficulty of locating nanomaterials. REACH undoubtedly changes the role of oversight departments, who verify the information provided to workers, but it does not transform oversight of the risks of nanomaterials: "I expected more. I thought I would have a means to take action" (Occupational physician); "REACH didn't change anything for nanomaterials" (Occupational physicianinspector). Thus, even if health and safety experts have technical knowledge that allows them to make use of REACH, in practice, they do not do so, as a result of the lack of steering and control over risk oversight.

Thus, nanomaterials are indeed innovative risks.

\section{CONCLUSION}

Nanomaterials represent a change in how technological risks are conceptualized for two reasons.

The first has to do with the possibility or impossibility of evaluating risks, given ongoing uncertainty about how to do this, as well as about workers' degree of exposure, since there is a lack of traceability of nanomaterials throughout their entire life cycle. Thus, among scientific researchers, there is agreement that there must be a change in the toxicological or eco-toxicological paradigm used: the paradigm of the dose-effect relationship must be replaced with a new paradigm, still to be defined, that would combine analysis of toxic effects with physical-chemical parameters that would vary depending on the manufacturing conditions of a given material. This necessity may have led to unpredicted scientific effects connected to the "safe by design" concept Suraud (2019), but it is quite far from receiving an operational response in terms of risk oversight.

The second reason has to do with the capacity of social theories to study risks after the emergence of debates but before pathologies have been identified. The problem expressed here can be understood in the light of the Collingridge dilemma Collingridge (1980): when technology is created, its negative effects cannot be predicted; when its negative effects appear, it has already spread more or less irreversibly throughout the economic and social fabric, making it difficult to give up.

Although research has long dealt with the need to open the innovation process up to users of technology Akrich (1991), it has primarily focused on the social uses of technology, rather than on issues of health and environmental effects. Proposals such as the "Constructive Technology Assessment" Rip and Kulve (2008) have advanced the debate by insisting on the procedural dimension of such assessments, and on the mechanisms for intervention they imply. However, to be legitimate, each procedure must fit within a framework that establishes universally shareable conditions 
regarding the raison d'être of its application, inorder to go beyond an overly empirical case-by-case basis. In particular, within the European Union, and especially in France, the issue of precaution cannot be ignored-that is, a policy of controlling the effects of technological applications before they are brought to a wide market. This is one possible response to the Collingridge dilemma, but it must be made official in the context of nanomaterials. This might mean developing an approach to shaping marketing authorization in such a way as to include civil society in the decision-making process. It is not obvious how such inclusion would be achieved, since it is not even part of the marketing authorization procedure for medications, which is by now quite old, but it would have the benefit of encouraging public debates.

Thus, social theories must create a research framework that will take into account all the work that has been done on public participation and public debate, but which will be specific to nanomaterials and nanoproducts as innovative risks.

\section{REFERENCES}

Aide au repérage des nanomatériaux en entreprise. (2014). INRS. Retrieved from https: / /www inrs.fr/media.html?refINRS=ED\%206174

Akrich, M. (1991). (ed) La gestion de la recherche. Nouveaux problèmes, nouveaux outils (Vinck \& D., Eds.). Paris: Editions De Boeck.

Borelle, C., \& Pélisse, J. (2017). Ça sent bizarre, ici ». La sécurité dans les laboratoires de nanomédecine (France, États-Unis). Sociologie du travail.

Bouffartigue, P. (2014). Retrieved from http://journals.openedition.org/nrt/1403

Brice, L. (2013). Les espaces politiques des substances chimiques. Définir des nanomatériaux internationaux, européens et français, 7(1), 195-221. Retrieved from https: / www .cairn.info/revue-anthropologie-des-connaissances-2013-1-page-195.htm

Chaskiel, P. (2013). Syndicalisme et nanotechnologies. De l'espace des relations professionnelles à l'espace public des risques. Sociologie du travail.

Chaskiel, P., \& Klein, E. (2017). Retrieved from https://www.jle.com/fr/revues/ers/ e-docs/un_effet_reach_dans_lindustrie_aeronautique_lobsolescence_reglementaire _du_chrome_vi_310460/article.phtml?tab=supp

Chaskiel, P., \& Suraud, M. G. (2014). Retrieved from https://doi.org/10.1051/nss/2014025 Collingridge, D. (1980). The Social Control of Technology. New-York: St. Martin's Press.

Counil, E., \& Henry, E. (2018). Retrieved from http://journals.openedition.org/pistes/ 5631DOI:10.4000/pistes.5631

Éric Drais. (2017). La prévention des risques émergents à l'épreuve du principe de précaution : le cas des nanomatériaux. Droit et société, $N^{\circ}$ 96(2), 305-305. Retrieved from https:// dx.doi.org/10.3917/drs.096.0305 10.3917/drs.096.0305

Ferron, P. J., Huet, S., Hogeveen, K., Fessard, V., \& Anses, L. L. H. (2015). Effects of food chemical contaminants in human HepaRG and Caco-2 cells using an automated microscopy and high content analysis based approach (Vol. 238). Elsevier BV. Retrieved from https:// dx.doi.org/10.1016/j.toxlet.2015.08.290 10.1016/j.toxlet.2015.08.290

Henry, E. (2007). Amiante : un scandale improbable. Sociologie d'un problème public. Rennes. Henry, E. (2017). Ignorance scientifique et inaction publique. Les politiques de santé au travail. Les Presses de Sciences Po. Paris. 
Johansson, M., \& Boholm, Å. (2017). Scientists' Understandings of Risk of Nanomaterials: Disciplinary Culture Through the Ethnographic Lens. NanoEthics, 11(3), 229-242. Retrieved from https://dx.doi.org/10.1007/s11569-017-0297-2 10.1007/s11569 -017-0297-2

Jouvenet, M. (2012). Nanosciences et nanotechnologies : une coopération modèle ? Terrain, 58, 44-63. https://doi.org/10.4000/terrain.14645

Jouzel, J.-N., \& Lascoumes, P. (2011). Le règlement REACH : une politique européenne de l'incertain. Un détour de régulation pour la gestion des risques chimiques (Vol. 33). CAIRN. Retrieved from https://dx.doi.org/10.3917/poeu.033.0185 10.3917/poeu .033 .0185

Kelty, C. M. (2009). Beyond Implications and Applications: the Story of 'Safety by Design'. NanoEthics, 3(2), 79-96. Retrieved from https://dx.doi.org/10.1007/s11569-009 -0066-y 10.1007/s11569-009-0066-y

Lacour. (n.d.). 2012 De l'innovation à l'utilisation des nanomatériaux : le cadre normatif des nanotubes de carbone. Paris: Éditions Larcier.

Lallain, C., Caroly, S., Drais, E., \& Witschger, O. (2015). Retrieved from http://pistes.revues $.0 \mathrm{rg} / 4421$

Les réalités industrielles dans le domaine des nanomatériaux en France Analyse de la réalité du poids des nanomatériaux dans la filière industrielle concernée. (2012). DGCIS. Retrieved from https://archives.entreprises.gouv.fr/.../realites-industrielles -nanomateriaux-france.pdf

Luhmann, N. (1995). Social Systems. Standford: Standford University Press.

Marichalar, P. (2014). Médecin du travail. In Presses de Sciences Po.

Mias, A. (2015). Autonomie des agents et légitimité de l'inspection du travail. La Nouvelle Revue du Travail(7). Retrieved from https://dx.doi.org/10.4000/nrt.2314 10.4000/ nrt.2314

Moriceau, C. (2009). Les perceptions des risques au travail dans la seconde moitié du. XIXe siècle : entre connaissance, déni et prévention, 1, 11-27. Retrieved from https://www .cairn.info/revue-d-histoire-moderne-et-contemporaine-2009-1-page-11.htm

Omnès, C. (2009). De la perception du risque professionnel aux pratiques de prévention : la construction d'un risque acceptable (Vol. 56-1). CAIRN. Retrieved from https://dx.doi .org/10.3917/rhmc.561.0061 10.3917/rhmc.561.0061

Rip, A., \& Kulve, H. (2008). Constructive Technology Assessment and Sociotechnical Scenarios. Nanotechnology in Society, I, 49-70.

Suraud, M.-G. (2019). From "Safe by Design" to Scientific Changes: Unforeseen Effects of Controversy Surrounding Nanotechnology in France. NanoEthics, 13(2), 103-112. Retrieved from https://dx.doi.org/10.1007/s11569-019-00343-6 10.1007/s11569 -019-00343-6

Thébaud-Mony, A. (1991). La reconnaissance des maladies professionnelles en France. Acteurs et logiques sociales. La Documentation Française. Paris.

Thébaud-Mony, A. (2007). Travailler peut nuire gravement à votre santé, Sous-traitance des risques, mise en danger d'autrui, atteintes à la dignité, violence physiques et morales, cancers professionnels. Paris. 